\title{
Freshly Isolated Hippocampal CA1 Astrocytes Comprise Two Populations Differing in Glutamate Transporter and AMPA Receptor Expression
}

\author{
Min Zhou and Harold K. Kimelberg \\ Center for Neuropharmacology and Neuroscience and Division of Neurosurgery, Albany Medical College, Albany, \\ New York 12208
}

We have shown previously that process-bearing GFAP+ astrocytes freshly isolated from rat hippocampus CA1 and CA3 regions are heterogeneous in ion channel expression and $\mathrm{K}^{+}$ uptake capabilities, such that two distinct populations of astrocytes can be described (Zhou and Kimelberg, 2000). In the present study, we report that glutamate transporter (GT) currents can only be measured from one type of these freshly isolated hippocampal CA1 astrocytes [variably rectifying astrocytes (VRAs)] but were not detectable in the second type of astrocyte [outwardly rectifying astrocytes (ORAs)]. The GT currents showed a strict $\mathrm{Na}^{+}$dependency and high affinity for glutamate $\left(\mathrm{EC}_{50}\right.$ of $\left.4 \pm 1.1 \mu \mathrm{M}\right)$. The astrocytes lacking GT currents (ORAs) showed an AMPA receptor current density
(55 $\mathrm{pA} / \mathrm{pF}$ ) that was 42-fold higher than VRAs (1.3 pA/pF). In contrast, the $\mathrm{GABA}_{\mathrm{A}}$ currents were of comparable current density in both types. The specificity of these differences makes it unlikely that they are attributable to preparative damage. Therefore, these findings strongly indicate that, within a single region of the hippocampus, GFAP + astrocytes comprise a functionally diverse population that are qualitatively different in their functional glutamate transporter and quantitatively different in their functional AMPA receptor expression. This heterogeneity implies that GFAP+ astrocytes may participate in or modulate glutamate synaptic transmission differently.

Key words: fresh cell isolation; hippocampus; GFAP+ astrocytes; glutamate transporter; AMPA receptor; patch-clamp
Accumulating evidence suggests that astrocytes may play both supportive and active roles in brain. This is particularly being shown in relation to excitatory synaptic transmission. Astrocytic glutamate transporters (GTs) have been shown to be primarily involved in maintaining low extracellular glutamate (Glu) levels in vivo (Rothstein et al., 1996; Anderson and Swanson, 2000). Astrocytes also have AMPA receptors (AMPA-Rs) originally shown in astrocytes in primary culture (Bowman and Kimelberg, 1984; Kettenmann et al., 1984) and then in situ and in freshly isolated preparations (Steinhäuser and Gallo, 1996). AMPA-R has been demonstrated to be potentially functional in in situ studies because perisynaptic glutamate concentrations may transiently rise to a sufficient level to activate astrocytic AMPA-Rs (Dzubay and Jahr, 1999). Astrocytes have been shown to respond to glutamate released from synaptic terminals in the hippocampal CA1 region by increases in intracellular $\mathrm{Ca}^{2+}$ via activation of both metabotropic and ionotropic glutamate receptors (Porter and McCarthy, 1996). One of the many possible consequences of astrocytic AMPA-R activation has been suggested to be the release of D-serine from astrocytes, which can then potentiate the postsynaptic NMDA receptor glycine site as an endogenous ligand to modulate synaptic transmission and plasticity (Baranano et al., 2001).

Electrophysiological studies of astrocytes identified morpholog-

Received March 29, 2001; revised July 16, 2001; accepted July 27, 2001.

This work was supported by National Institutes of Health Grant NS 19492 to H.K.K. We thank Drs. Mark W. Fleck and Sally Temple for the comments on this manuscript and Carol J. Charniga for excellent technical assistance.

Correspondence should be addressed to Dr. Harold K. Kimelberg, Center for Neuropharmacology and Neuroscience, MC-60, Albany Medical College, 47 New Scotland Avenue, Albany, NY 12208. E-mail: kimelbh@mail.amc.edu.

Copyright (C) 2001 Society for Neuroscience $0270-6474 / 01 / 217901-08 \$ 15.00 / 0$ ically in situ (D'Ambrosio et al., 1998) and in GFAP + cells in freshly isolated preparations (Zhou and Kimelberg, 2000) have indicated that hippocampal astrocytes are heterogeneous in their ion channel expression. The question we asked here is whether these differences in ion channel expression are also associated with differences in glutamate transporter and AMPA-R currents.

We studied glutamate transporter and AMPA-R currents using freshly isolated astrocytes (FIAs) and a fast perfusion drug delivery system to resolve the Glu-induced current under conditions favorable to activation of both astrocytic AMPA-R and glutamate transporter currents. As a comparison, we also analyzed $\mathrm{GABA}_{\mathrm{A}}$ receptor-mediated current because $\mathrm{GABA}_{\mathrm{A}}$ has been shown in acutely isolated astrocytes also from hippocampus (Fraser et al., 1995). Our data show that GFAP+ astrocytes freshly isolated from the hippocampal CA1 region of postnatal day 7 (P7) to P35 rats comprise two subpopulations with quite different functional properties in regard to functional glutamate transporter currents and AMPA-Rs, in addition to the previously identified difference in regard to ion channel currents.

\section{MATERIALS AND METHODS}

Cell isolation. The procedure for preparation of FIAs has been described in detail previously (Zhou and Kimelberg, 2000) and is performed in accordance with a protocol approved by the Albany Medical College Institutional Animal Care and Use Committee. Briefly, hippocampal slices were prepared from 7- to 35-d-old Sprague Dawley rats and maintained in a $\mathrm{Ca}^{2+}$-free solution containing (in $\mathrm{mM}$ ): $124 \mathrm{NaCl}, 5 \mathrm{KCl}$, $2 \mathrm{MgSO}_{4}, 1$ Na-pyruvate, $26 \mathrm{NaHCO}_{3}$, and 10 glucose (bubbled with $95 \%$ $\mathrm{O}_{2}-5 \% \mathrm{CO}_{2}$ for $1 \mathrm{hr}$ ). Subsequently, the slices (six to eight from each animal) were transferred into standard artificial CSF solution containing $24 \mathrm{U} / \mathrm{ml}$ papain and $0.24 \mathrm{mg} / \mathrm{ml}$ cysteine and bubbled with $95 \% \mathrm{O}_{2}-$ $5 \% \mathrm{CO}_{2}$ at $22^{\circ} \mathrm{C}$ for $30 \mathrm{~min}$. The enzymatic digestion was halted by thorough washing of the slices in $\mathrm{Ca}^{2+}$-free solution. The slices were then stored in the $\mathrm{Ca}^{2+}$-free solution for at least $1 \mathrm{hr}$ before trituration. 
B

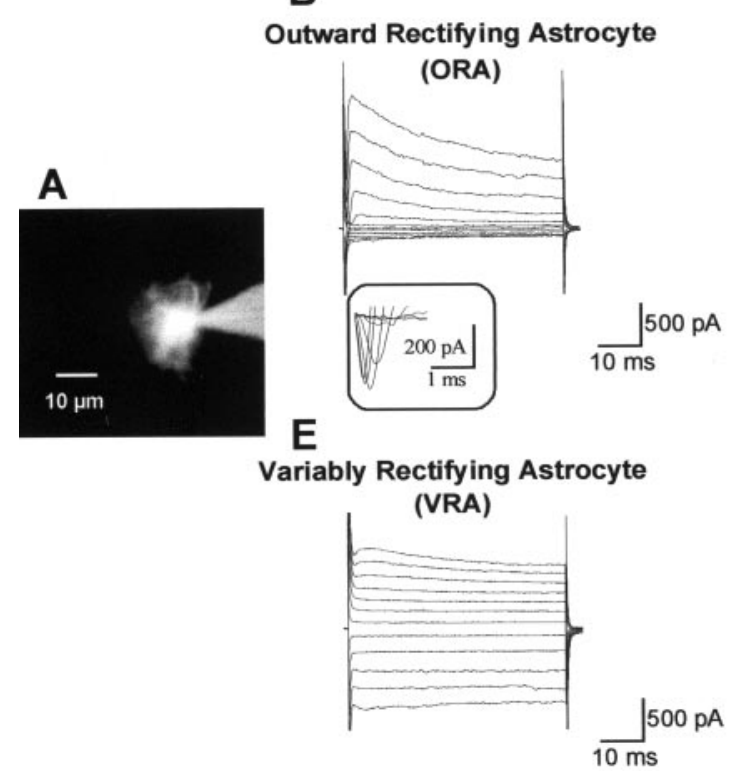

C

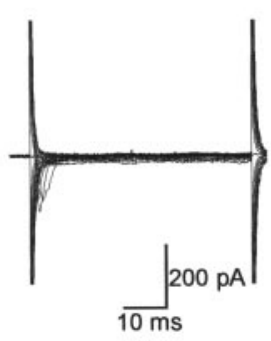

$\mathbf{F}$

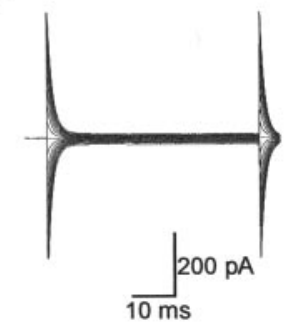

D

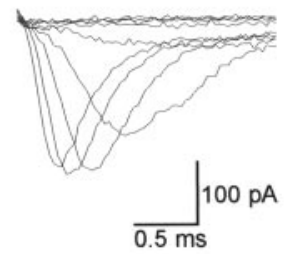

G

Figure 1. Morphology and current profiles of ORAs and VRAs. A, Imaging of a freshly isolated astrocyte during recording with Lucifer yellow dye $(0.3 \%)$, in the pipette, showing bushy processes extending from the cell body. The processes are not very distinct because there is some folding back of the processes and because of the out-of-focus fluorescence halo, as this photograph was taken through the nonconfocal Nikon Diaphot microscope we used in the recording set up. $B, E$, Membrane currents induced by voltage steps $(50 \mathrm{msec})$ from -160 to $+60 \mathrm{mV}(20 \mathrm{mV}$ increments $)$ with a $\mathrm{NO}_{3}{ }^{-}$-based pipette solution (see Materials and Methods). ORAs $(B)$ are characterized by a dominant expression of outward $I \mathrm{~K}_{\mathrm{a}}$ and $I \mathrm{~K}_{\mathrm{dr}}$ plus small inward $I \mathrm{Na}{ }^{+}$ currents (see inset below $B$ ). VRAs $(E)$ are characterized by a symmetric expression of inward and outward potassium currents. $C, F$, When $\mathrm{K}^{+}$ channel-mediated currents were completely masked by the substitution of pipette $\mathrm{K}^{+}$with $\mathrm{Cs}^{+}$, an ORA $(C)$ and a VRA $(F)$ were identified based on their identical bushy morphology but marked different membrane capacitances $(10.5 \mathrm{pF}$ in recording $C$ and $38 \mathrm{pF}$ in $F)$. The $I \mathrm{Na}^{+}$is shown in higher resolution in $C . I \mathrm{Na}^{+}$currents were never observed in VRAs $(F) . D$ and $G$ are recordings $C$ and $F$, respectively, at higher resolution and after off-line compensation for leak and capacitance.

In some preparations, FIAs were prepared without the $1 \mathrm{hr}$ preenzymatic and postenzymatic incubation in $\mathrm{Ca}^{2+}$-free solution to verify that these preparation steps do not cause the differences seen in FIAs. Before recording from the freshly isolated astrocytes, the CA1 stratum radiatum was dissected out under the microscopic to avoid the inclusion of any part of the dentate gyrus, which may contain GFAP+ stem cells (Liu et al. 2000). The dissected stratum radiatum of the CA1 region was then triturated into the recording chamber. Only "bushy," process-bearing astrocytes were selected for recording, which in our previous studies were shown to be both GFAP mRNA+ and GFAP + (Zhou and Kimelberg, 2000; Schools and Kimelberg, 2001).

Solutions and drugs. The standard bath solution contained (in mM): 150 $\mathrm{NaCl}, 5 \mathrm{KCl}, 2 \mathrm{MgCl}_{2}, 2 \mathrm{CaCl}_{2}, 10$ glucose, and $10 \mathrm{HEPES}$, $\mathrm{pH}$ adjusted to7.4 with $\mathrm{NaOH}$. The pipette solutions contained (in mM): $140 \mathrm{KNO}_{3}$ (or KSCN), $0.5 \mathrm{CaCl}_{2}, 1 \mathrm{MgCl}_{2}, 5$ EGTA, 10 HEPES, $3 \mathrm{Mg}$-ATP, and $0.3 \mathrm{Na}-\mathrm{GTP}, \mathrm{pH}$ adjusted to 7.25 with $\mathrm{KOH}$. To measure $\mathrm{GABA}_{\mathrm{A}}$ receptor-mediated $\mathrm{Cl}^{-}$currents without contamination by $\mathrm{K}^{+}$channelmediated currents, the bath solution contained (in $\mathrm{mM}$ ): $119 \mathrm{NaCl}, 5$ $\mathrm{BaCl}_{2}, 2 \mathrm{CaCl}_{2}, 3 \mathrm{~mm} \mathrm{CsCl}, 5 \mathrm{KCl}, 2 \mathrm{MgCl}_{2}, 10$ glucose, and $10 \mathrm{HEPES}$. Also $140 \mathrm{~mm} \mathrm{KCl}$ was substituted by an equimolar amount of $\mathrm{CsCl}$ in the pipette solution.

2,3-Dihydroxy-6-nitro-7-sulfonyl-benzo[F]quinoxaline (NBQX), 2,3benzodiazepine $\left(\mathrm{GYKI}_{52466}\right)$, GABA, muscimol, and bicuculline were purchased from Tocris Cookson (Ballwin, MO). NBQX and GYKI ${ }_{52466}$ were dissolved in dimethylsulfoxide at 1 and $10 \mathrm{~mm}$, respectively, before dilution in the bath solution. Dihydrokainate (DHK), D,L-threo- $\beta$ hydroxyaspartate (THA), and all of the salts and reagents were purchased from Sigma (St. Louis, MO).

Electrophysiology. Whole-cell membrane currents were measured by an Axopatch 200B amplifier (Axon Instruments, Foster City, CA) and sampled by a TL-1 DMA Interface (Axon Instruments). Data acquisition was by pClamp 6.0.4 software (Axon Instruments). Low-resistance patch pipettes (3-6 M $\Omega$ ) were fabricated from borosilicate capillaries (outer diameter, $1.5 \mathrm{~mm}$; Warner Instruments, Hamden, CT) using a Flaming/ Brown Micropipette Puller (model P-87; Sutter Instruments, Novato, CA). Capacitance and series resistance $\left(R_{S}\right)$ compensation $(40 \sim 50 \%)$ were used to improve voltage-clamp control. Membrane capacitance
$\left(C_{\mathrm{m}}\right)$ and series resistance $\left(R_{\mathrm{S}}\right)$ were determined by a depolarizing test pulse from -70 to $-60 \mathrm{mV}(10 \mathrm{msec}$, filter at $10 \mathrm{kHz}$, sampling at 30 $\mathrm{kHz}$ ). In some experiments, $0.3 \%$ Lucifer yellow was added to the pipette solution to more distinctly show the complete astrocyte morphology. Drugs were rapidly applied to the established whole-cell patches through square tubes of the Perfusion Fast-Step System (SF-77; Warner Instruments) controlled by programmed data acquisition protocols. Experiments were performed at room temperature $\left(\sim 20-24^{\circ} \mathrm{C}\right)$. The microscope used was a Nikon (Tokyo, Japan) Diaphot inverted stage equipped with phase contrast and fluorescence optics.

Data analysis. Data are given as means \pm SEM. The dose-response curve was fitted by the following equation: $I=I_{\max }\left\{1 /\left[1+\left(\mathrm{EC}_{50} /\right.\right.\right.$ $\left.\left.[\mathrm{Glu}])^{n}\right]\right\}$. Significance differences were evaluated according to the Student's $t$ test. The level of significance was set at $p<0.05$.

\section{RESULTS}

\section{Morphology and ion channel expression of freshly isolated astrocytes}

Outwardly rectifying astrocytes (ORAs) and variably rectifying astrocytes (VRAs) could not be morphologically distinguished; both were bushy, process-bearing cells resembling the classical descriptions of protoplasmic astrocytes (Privat and Rataboul, 1986). A representative bushy astrocyte filled with Lucifer yellow dye during the recording is shown in Figure $1 A$. These cells are $\geq 95 \%$ GFAP + by immunocytochemistry (Schools and Kimelberg, 2001). In Figure $1, B$ and $E$, we show the two distinct ion channel profiles that we reported previously (Zhou and Kimelberg, 2000). One type, the ORA, is characterized by a dominant expression of voltage-gated outward potassium currents $\left(I \mathrm{~K}_{\mathrm{a}}\right.$ and $\left.I \mathrm{~K}_{\mathrm{dr}}\right)$ and inward sodium current $\left(I \mathrm{Na}^{+}\right)$(Fig. $1 B$, inset). The second type, the VRA, is distinguished by a pronounced expression of leak $\mathrm{K}^{+}$current $\left(I \mathrm{~K}_{\mathrm{ohm}}\right)$ and low-density expression of $I \mathrm{~K}_{\mathrm{a}}$ plus $I K_{\mathrm{dr}}$ (Zhou and Kimelberg, 2000). To further verify that 
A: ORA

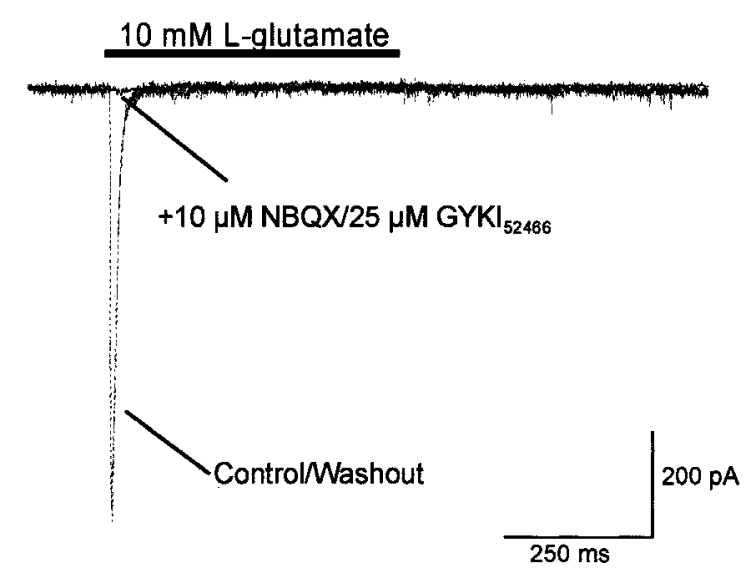

B: VRA

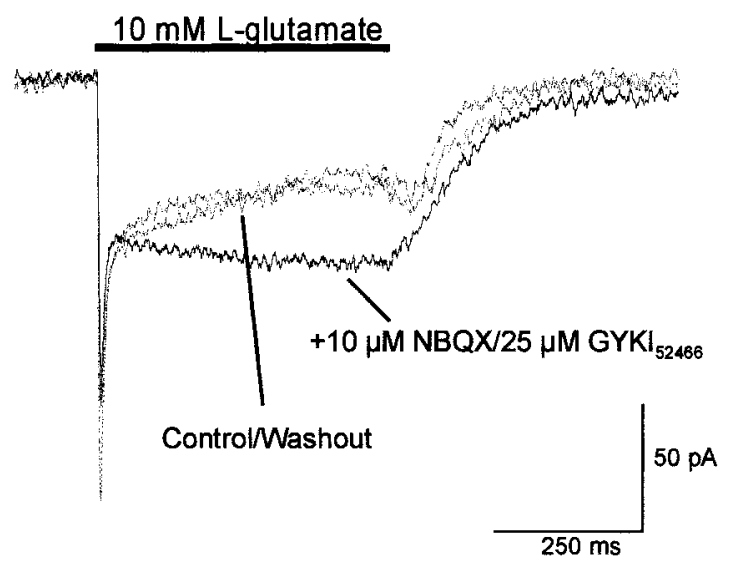

Figure 2. Differential expression of GT and AMPA-R currents by VRAs and ORAs. With $\mathrm{NO}_{3}{ }^{-}$as the major intracellular anion, 10 mM Glu (at -70 $\mathrm{mV}$ ) evoked a fast activating and rapidly desensitizing inward current in ORAs (dashed traces in $A$ ). The response to the same Glu application in VRA showed the initial transient plus a substantial steady-state current during the $0.5 \mathrm{sec}$ Glu pulse (dashed traces in $B$ ). The selective AMPA-R antagonists NBQX $(10 \mu \mathrm{M})$ plus GYKI ${ }_{52466}(25 \mu \mathrm{M})$ completely blocked the Glu-induced current in the ORA (solid trace in $A$ ). In the VRA, however, the same antagonists reduced the initial peak current by only $34 \%$ and potentiated the steady-state current by $40 \%$ (solid trace in $B$ ). In both cases, $\mathrm{NBQX}-\mathrm{GYKI} \mathrm{I}_{52466}$ was applied $250 \mathrm{msec}$ before the Glu pulse to ensure a complete block of AMPA activation. The dashed traces in $A$ and $B$ are the superimposed Glu-evoked currents of the initial control and then after washout of the AMPA-R antagonists. Both recordings $A$ and $B$ were in cells from P11 rats.

$I \mathrm{Na}^{+}$is a characteristic feature of ORA and also to rule out the possibility that VRA type astrocytes also express $I \mathrm{Na}^{+}$but this small $I \mathrm{Na}^{+}$is obscured by the abundant $I \mathrm{~K}_{\mathrm{ohm}}$, we performed experiments in which $\mathrm{K}^{+}$was substituted by $\mathrm{Cs}^{+}$in the pipette solution (see Materials and Methods) to mask the activation of any $\mathrm{K}^{+}$channel-mediated current (Fig. $1 C, F$ ). Under these conditions, VRAs show a larger membrane capacitance $(32.8 \pm 5.4$ $\mathrm{pF} ; n=10)$ than ORAs $(10.2 \pm 2.7 \mathrm{pF} ; n=12)$, as we described previously (Zhou and Kimelberg, 2000). However, although enhanced $I \mathrm{Na}^{+}$could be seen in ORAs $(n=12)($ Fig. $1 D)$, no $I \mathrm{Na}^{+}$ could be detected in VRAs $(n=10)$ (Fig. $1 G)$. This result confirmed our previous observations that $I \mathrm{Na}^{+}$seems a diagnostic criteria in distinguishing ORAs from VRAs.

\section{Selective expression of glutamate transporter currents by VRAs}

The translocation of Glu via GTs is driven by the transmembrane $\mathrm{Na}^{+}, \mathrm{K}^{+}$gradients, which generates a small but measurable coupled charge movement. It also has been shown that GT activation is associated with an anion conductance that is $\sim 10$ fold larger than the GT-coupled charge movement (Fairman et al., 1995; Bergles and Jahr, 1997). In the dominant astrocytic GT isoform, GLT-1 (also termed EAAT2), the uncoupled anion conductance displays a similar kinetics to coupled charge movement and thus likely precisely reflects Glu transport (Otis and Kavanaugh, 2000). We used the highly permeant anions $\mathrm{NO}_{3}{ }^{-}$or $\mathrm{SCN}^{-}$in the pipette solution to predominantly measure the anion conductance (Fairman et al., 1995; Wadiche et al., 1995). Under these recording conditions, the basic ion channel profiles for both ORA and VRA did not differ from KCl-based solution. However, the whole-cell $I-V$ relationship of VRAs showed a $10.8 \pm 7.8 \mathrm{mV}$ positive shift in reversal potential $(n=25$; data not shown) compared with the KCl-based pipette solution, suggesting the existence of a persistent resting inward conductance when $\mathrm{NO}_{3}{ }^{-}$is the major anion in the pipette solution. As demonstrated in previous studies, this resting conductance is an indicator of anions leaving the cell via the GT-associated anion pathway
(Bergles and Jahr, 1997; Levy et al., 1998; Otis and Jahr, 1998; Otis and Kavanaugh, 2000)

During fast application of a saturating concentration of L-Glu (10 $\mathrm{mm}$ ) at $-70 \mathrm{mV}$ holding potential, ORAs showed a typical astrocytic AMPA-R response (Seifert et al., 1997), characterized by a fast activation and a rapid and almost complete desensitization (Fig. $2 A$, dashed trace). The peak amplitude was $-498 \pm 50.6$ pA $(n=21)$. VRAs showed a smaller peak current amplitude of $-101 \pm 25 \mathrm{pA}$ but a larger steady-state current amplitude of $-22 \pm 6.9 \mathrm{pA}(n=11)$ (Fig. $2 B$, dashed trace $)$. The Glu-evoked current in ORAs was completely abolished by the selective AMPA-R antagonists NBQX $(10 \mu \mathrm{M})$ plus $\mathrm{GYKI}_{52466}(25 \mu \mathrm{M})$ (Fig. 2A). For VRAs, however, the peak current amplitude was only partially blocked by these antagonists (reduced by $50.6 \pm$ $10.7 \% ; n=11)$. Additionally, the steady-state currents were enhanced by an average of $40 \pm 12 \%$ at the end of Glu pulse (result from one cell is shown in Fig. 2B, solid trace). This NBQX-GYKI ${ }_{52466}$-insensitive current had an initial peak current of $-54 \pm 6 \mathrm{pA}$ and a steady-state current of $-43.7 \pm 4.1 \mathrm{pA}$ $(n=11)$, which are very similar to the kinetics of GT currents identified from patches excised from CA1 astrocytes from hippocampal slices (Bergles and Jahr, 1997).

We further determined that the NBQX-GYKI $I_{52466}$-resistant currents seen in VRAs were GT-associated currents by the following experiments. First, substitution of extracellular $\mathrm{Na}^{+}$by $\mathrm{Li}^{+}$completely abolished this current $(n=3)$ (Fig. $\left.3 A\right)$. Second, THA, a transportable, competitive inhibitor of all of the GTs so far identified, induced a sustained inward current and also prevented Glu from inducing any additional current at the $-70 \mathrm{mV}$ holding potential $(n=4)$ (Fig. $3 B)$. We did not see any THAinduced currents in ORAs $(n=5$; data not shown). Finally, assuming the NBQX-GYKI-insensitive current is purely carried by $\mathrm{NO}_{3}{ }^{-}$and the relative permeability of $P_{\mathrm{Cl}}{ }^{-} / P_{\mathrm{NO} 3}{ }^{-} \sim 0.07$ (Wadiche and Kavanaugh, 1998), the reversal potential of this current should approach the $E_{\mathrm{NO} 3}$ of $\sim 70 \mathrm{mV}$. As shown in Figure 3, $C$ and $D$, the Glu-induced NBQX-GYKI ${ }_{52466}$-resistant 


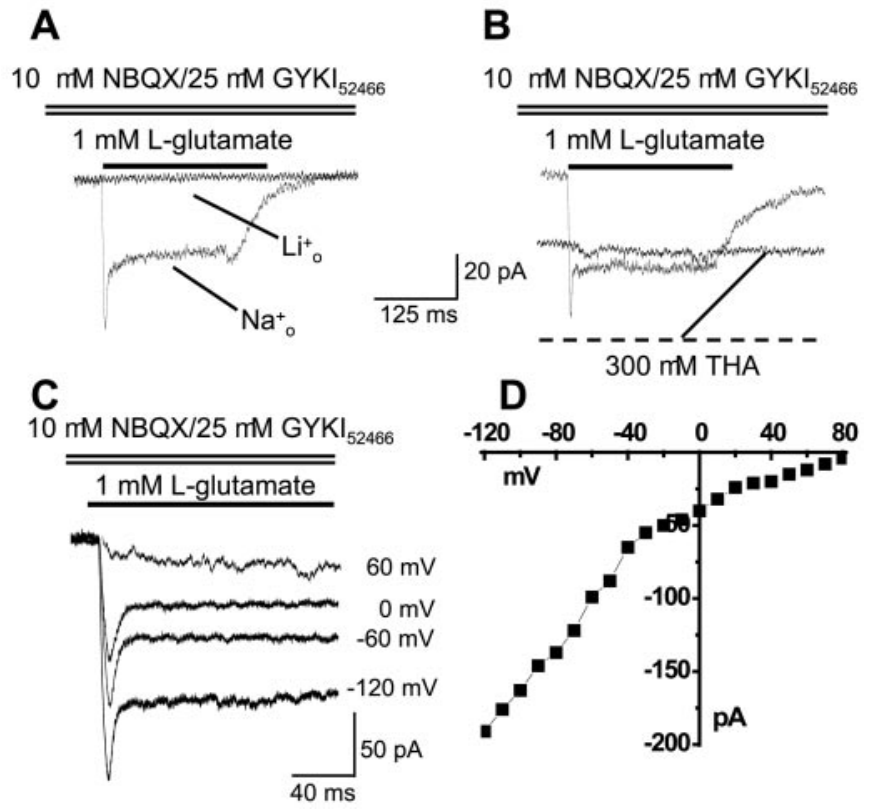

Figure 3. NBQX-GYKI 52466 -resistant currents in VRAs are GTassociated currents. $A$, Substitution of extracellular $\mathrm{Na}^{+}$by $\mathrm{Li}^{+}$completely abolished the Glu-induced NBQX-GYKI ${ }_{52466}$-insensitive current. $B$, THA, a transportable GT inhibitor, induced a sustained inward current and blocked any Glu-generated additional current in the same cells. Cells were clamped at $-70 \mathrm{mV}$ throughout. $C, D$, With $140 \mathrm{~mm}$ $\mathrm{NO}_{3}{ }^{-}$in the pipette and $150 \mathrm{~mm} \mathrm{Cl}^{-}$in the bath solution, the NBQXGYKI-resistant inward current persisted until the voltage steps reached +70 to $+80 \mathrm{mV}$, consistent with a primary $\mathrm{NO}_{3}{ }^{-}$identity of this current $\left(E_{\mathrm{NO} 3} \sim 70 \mathrm{mV}\right)$. Recordings $A-C$ were obtained in VRAs from P7, P12, and $\mathrm{P} 10$ animals, respectively.

inward currents (after off-line subtraction of inward and outward potassium currents) persisted up to approximately $+70 \mathrm{mV}(n=$ 3 ). These data together support activation of $\mathrm{Na}^{+}$-dependent GT currents on VRAs.

\section{Absence of GT currents in ORAs is independent of the anions used or age of animals}

Because GT currents were not detected in ORAs under our standard condition, we next asked whether ORAs express functional GT isoforms but at a relatively low density. Thus, their GT currents might only be seen with anions having a higher permeability than $\mathrm{NO}_{3}{ }^{-}$. Therefore, we also used $\mathrm{SCN}^{-}$, which gives the largest anion conductance for all of the identified GTs so far (Palacin et al., 1998). As shown in Figure 4, $A 1$ and $A 2$, the Glu-induced current with $\mathrm{SCN}^{-}$in the pipette was also completely blocked by NBQX-GYKI ${ }_{52466}$ in ORAs $(n=3)$.

We observed that, in older animals (P18-P30), 27\% of ORAs additionally express a small inward $\mathrm{K}^{+}$currents $\left(I \mathrm{~K}_{\mathrm{in}}\right)$ (Fig. 4B1) (Zhou and Kimelberg, 2000). Such an ion channel profile has been suggested recently, reflecting a developmental switch in ion channel expression (Brockhaus and Deitmer, 2000). This could also include a gain of GTs, so we tested this by recording from ORAs from P25-P35 rats that show $I \mathrm{~K}_{\mathrm{in}}$. Glu at $1 \mathrm{~mm}$ induced an average peak current of $-477 \pm 172 \mathrm{pA}(n=8)$ and a steady-state current of $-9 \pm 6.1 \mathrm{pA}(n=8)$, closely matching the peak and steady-state current values of ORAs measured from the earlier developmental stages (see previous section of Results). This Glu-induced current (Fig. 4B2) was also completely blocked by NBQX-GYKI ${ }_{52466}$, (Fig. 4B3), showing that no GT currents are present in the ORAs isolated from older animals that show

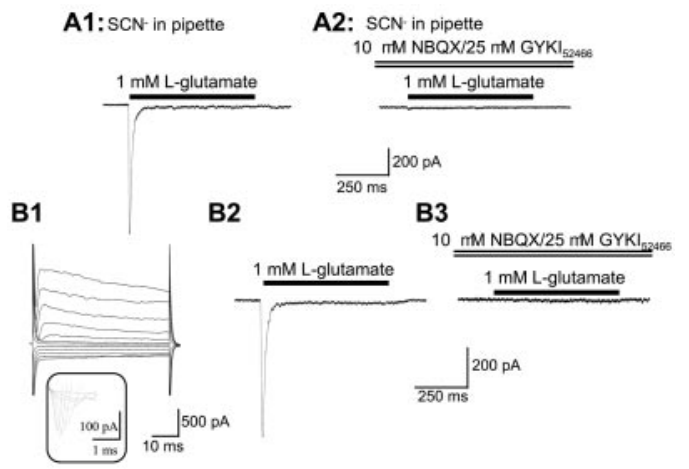

Figure 4. The absence of GT currents in ORAs is independent of the permeant intracellular anion and animal age. $A 1$ and $A 2$ show an ORA recording with $\mathrm{SCN}^{-}$as the major anion in the pipette solution. Glu at 1 $\mathrm{mM}$ induced a fast activation and rapidly desensitizing inward current (A1), which was completely blocked by NBQX-GYKI $I_{52466}(A 2)$. B1 shows an ORA from a P31 rat, characterized by the expression of $I \mathrm{Na}^{+}$ (see the inset below B1) and also shows a small $I \mathrm{~K}_{\mathrm{in}}$ in response to hyperpolarization voltage steps (same voltage commands as in Fig. 1). The Glu-evoked current from this cell (B2) had the same kinetics as in $A 1$, and the current was completely abolished by NBQX-GYKI $\mathrm{G}_{52466}(B 3)$.

significant $I \mathrm{~K}_{\text {in }}$ (Fig. 4B1). These data further supports the view that ORAs are a persistent and distinct astrocytic subtype.

Although the specificity we observed from FIAs seems unlikely to be attributable to preparative damage because ORAs and VRAs experienced the same isolation procedure, we did reduce the time of the isolation procedure. We found both the specificity of ion channel profiles ( $n=2$ for ORAs; $n=4$ for VRAs) and GT and AMPA-R responses remained (data not shown) with the omission of the $2 \mathrm{hr}$ incubation of slices in $\mathrm{Ca}^{2+}$-free solution (see Materials and Methods).

\section{GTs in VRAs show varied sensitivity to DHK and show high-affinity glutamate uptake}

To explore whether different GT isoforms contribute to the GT current in VRAs, we tested the DHK sensitivity in VRAs isolated from P7-P14 rats. We found that the specific GLT-1 inhibitor DHK at $300 \mu \mathrm{M}$ induced a sustained resting outward current in the VRAs (13.4 $\pm 1.2 \mathrm{pA} ; n=7)$, presumably attributable to blockade of a resting anion conductance associated with GTs, as seen in excised astrocytic soma patches (Bergles and Jahr, 1997). Figure 5 is a representative recording showing the upward shift in basal current when $300 \mu \mathrm{M}$ DHK was applied before Glu and then the inhibition of both the peak and steadystate GT currents during a Glu pulse. DHK at $300 \mu \mathrm{M}$ inhibited the peak and steady-state GT currents by $41 \pm 9.3 \%$ (range of $12-82 \% ; n=7$ ) and $36.4 \pm 10.6 \%$ (range of $0-72 \% ; n=7$ ), respectively. The varied partial inhibition of GT currents by DHK is consistent with a coexistence of GLT-1 and the other glial type GT isoform GLAST, as seen at this developmental stage (Furuta et al., 1997; Lehre and Danbolt, 1998). P7-P14 is the time period that GLT starts to replace GLAST as the dominant GT isoform (Furuta et al., 1997).

The peak to steady-state current amplitude ratios in our wholecell recordings were $\sim 1.3$, which is lower than the value recorded from small excised patches, typically $\sim 4$ (Bergles and Jahr, 1997). Because the FIAs have an intricate morphology, a synchronized peak response of all of the GTs currents in one cell may be practically impossible, even with Glu applied to the isolated cells using a rapid delivery system. Thus, to estimate the Glu $\mathrm{EC}_{50}$, 


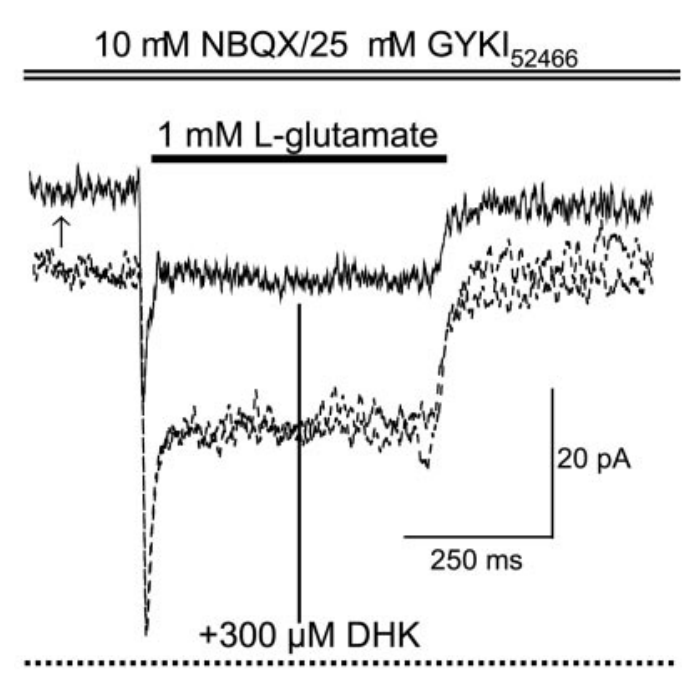

Figure 5. GT current blockade by the selective GLT-1 inhibitor DHK. All of the recording traces were obtained at an identical holding potential of $-70 \mathrm{mV}$. NBQX-GYKI ${ }_{52466}$ were present throughout the recording to block AMPA-R currents. The dashed lines are the GT current in control and after washout of DHK. The solid line trace shows the effect of addition of $300 \mu \mathrm{M}$ DHK. DHK was applied before the Glu pulse and continued throughout (as indicated by the dotted horizontal line at the bottom). DHK reduced the negative holding current $(-70 \mathrm{mV})$ when Glu was absent $(13$ pA upward shift as indicated by arrow). DHK also inhibited the Gluevoked peak current by $38 \%$ and steady-state current by $40 \%$ in this cell. Recording traces were obtained from a P13 rat. See Results for the variability in the magnitude of DHK blockade.

only the steady-state GT currents were used for our doseresponse analysis. In representative recordings shown in Figure $6 A$, the steady-state current amplitude values of the GT currents of VRAs were measured at different Glu concentrations and normalized to the current obtained for $1 \mathrm{~mm}$ Glu from the same cell to give the dose-response curve shown in Figure $6 B$. The best fit to the Hill equation gave a Glu $\mathrm{EC}_{50}$ of $4 \pm 1.1 \mu \mathrm{M}$ with a Hill coefficient $\left(n_{\mathrm{H}}\right)$ of 0.6 , supporting a high-affinity uptake of Glu by VRA GTs. This EC $_{50}$ is approximately threefold lower than the value analyzed from steady-state GT currents of excised patch of somatic membrane of hippocampal astrocytes $\left(\mathrm{EC}_{50}\right.$ of $13 \mu \mathrm{M}$ ) but with a comparable $n_{\mathrm{H}}$ of 0.59 at the same developmental stage (Bergles and Jahr, 1997). Possible reasons for the difference are covered in Discussion.

\section{ORAs show a higher AMPA-R current density than VRAs}

We noticed in measuring the GT currents (Fig. 2) that the currents sensitive to AMPA antagonists were much smaller in VRAs than in ORAs for cells from P7-P14 rats. These differences are summarized in Table 1, which includes data from P7-P14 and P25-P30 rats. It can be seen that the average peak AMPA-R current density of ORAs for both age groups is 42-fold greater than VRAs.

\section{ORAs and VRAs show comparable $\mathrm{GABA}_{\mathrm{A}}$ receptor currents}

The opposite differences in GTs and AMPA-R current expression, together with our finding of distinct ion channel profiles, argues against the differences in ORAs and VRAs are attributable to physical damage, which seems unlikely to produce such two distinct populations of cells. To further explore whether, or to what extent, the enzyme treatment can affect the measurement of receptors, transporter, or ion channel proteins, we measured GABA-mediated currents because $\mathrm{GABA}_{\mathrm{A}}$ receptors show the highest sensitivity to papain treatment in hippocampal neurons in situ (McCarren and Alger, 1987). In these experiments, we used a $\mathrm{Cs}^{+}$-based pipette solution to block $\mathrm{K}^{+}$channel-mediated currents. Therefore, ORAs and VRAs were identified based on the criteria of the presence of $I \mathrm{~N}_{\mathrm{a}}{ }^{+}$in ORAs (Fig. 1C) and the absence of $I \mathrm{~N}_{\mathrm{a}}{ }^{+}$in VRAs (Fig. $1 F$ ). As shown in Figure 7, $A 1$ and $B 1,1 \mathrm{~mm}$ GABA induced a robust inward current in both ORAs $(-829 \pm 259 \mathrm{pA} ; n=6)$ and VRAs $(-1092 \pm 359 \mathrm{pA}$; $n=5)$, with similar activation and desensitization kinetics. This GABA-induced current was inhibited similarly by the selective $\mathrm{GABA}_{\mathrm{A}}$ antagonist bicuculline $(10 \mu \mathrm{M})$ (Fig. 7A2,B2; Table 2). Also, the selective $\mathrm{GABA}_{\mathrm{A}}$ agonist muscimol $(50 \mu \mathrm{M})$ induced similar inward currents in both ORAs and VRAs (Fig. 7A3,B3; Table 2). This expression of $\mathrm{GABA}_{\mathrm{A}}$ current in both ORAs and VRAs is in agreement with the study by Fraser et al. (1995) using freshly isolated hippocampal GFAP + astrocytes. Our overall analysis revealed that the $\mathrm{GABA}_{\mathrm{A}}$ receptor current density is 3.3-fold higher in ORAs as compared with VRAs (Table 2), but this difference was not statistically different. The overall pharmacology profiles were the same (Table 2). These results indicate that papain treatment did not differentially alter the characteristics of functional $\mathrm{GABA}_{\mathrm{A}}$ receptors in ORAs and VRAs, if they are similarly expressed in both types.

\section{A}

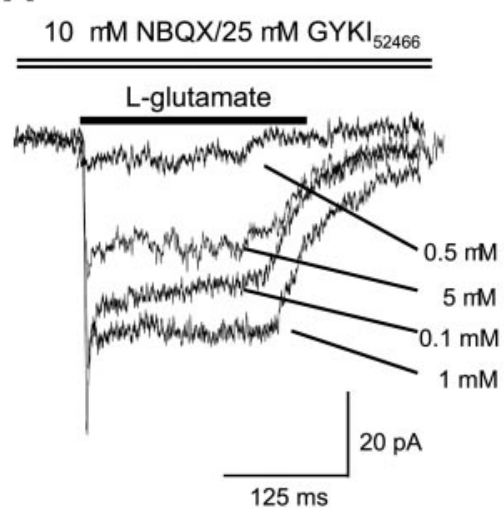

B

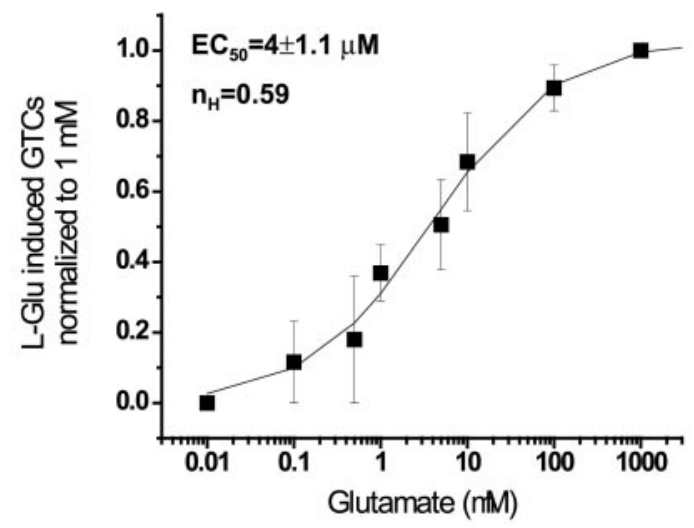

Figure 6. GT currents in VRAs show high Glu affinity for L-glutamate. $A$, Representative GT current traces induced by a series of Glu concentrations in a P10 VRA. B, Current amplitudes of the steady-state Glu-induced GT currents at different concentrations of Glu were normalized to the corresponding response evoked by $1 \mathrm{~mm}$ Glu in the same cell. Each data point represents the mean from three cells. Error bars show SEMs. Smooth line gives the best fit according to the Hill equation (see Materials and Methods), yielding an $\mathrm{EC}_{50}$ of $4 \pm 1.1 \mu \mathrm{M}$ and $n_{\mathrm{H}}$ of 0.6. 
Figure 7. $\mathrm{GABA}_{\mathrm{A}}$ receptor currents are comparable in ORAs and VRAs. $A 1-A 3$ and $B 1-B 3$ are recordings from an ORA and a VRA, respectively, at holding potential of $-70 \mathrm{mV}$. In $A 1$ and $B 1$, a $0.5 \mathrm{sec} 1 \mathrm{~mm}$ GABA pulse induced robust inward currents in both cells with a similar desensitization time course. At the end of the GABA pulse, the initial peak current $\left(A_{\mathrm{P}}\right)$ desensitized $47 \%$ in $A 1$ and $40 \%$ in $B 1 . A 2$ and $B 2$ show the similar inhibition of GABA-induced currents by the selective $\mathrm{GABA}_{\mathrm{A}}$ antagonist bicuculline $(10 \mu \mathrm{M})$. The GABAinduced currents were reduced by 52 and $64 \%$ in an ORA $(A 2)$ and a VRA (B2), respectively. $A 3$ and $B 3$ were the responses induced by the selective $\mathrm{GABA}_{\mathrm{A}}$ receptor agonist muscimol (50 $\mu \mathrm{M})$. In $A 3$ and $B 3$, the muscimolinduced peak current amplitudes amounted to 61 and $64 \%$ of the GABA induced currents. All recordings in $A$ and $B$ represent the same respective cells.

Table 1. ORAs show abundant AMPA-R current densities compared with VRAs

\begin{tabular}{lcc} 
& AMPA-R currents $(\mathrm{pA})$ & AMPA-R current density $(\mathrm{pA} / \mathrm{pF})$ \\
\hline ORA (P7-P14) & $-498 \pm 51(n=21)$ & $55.0 \pm 5.6(n=21)$ \\
ORA (P25-P35) & $-477 \pm 172(n=8)$ & $54.5 \pm 3.2(n=8)$ \\
VRA (P7-P35) & $-47 \pm 17^{*}(n=11)$ & $1.3 \pm 0.3^{*}(n=11)$ \\
ORA/VRA & 10.5 & 42
\end{tabular}

*Indicates significant differences between ORA and VRA (Student's $t$ test; $p<0.05$ ). For ORA/VRA calculation; ORAs from both P7-P14 and P25-P35 were included.

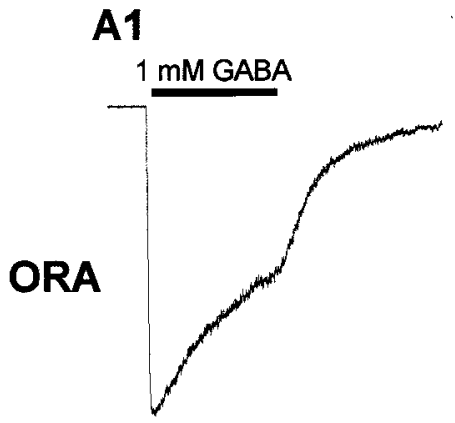

A2 $1 \mathrm{mM}$ GABA10 $\mu \mathrm{M}$ Bicuculline

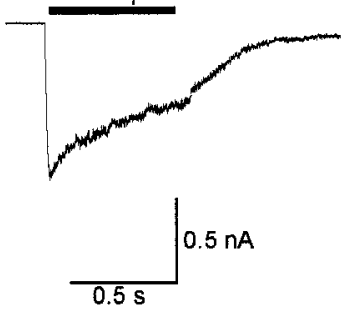

B1

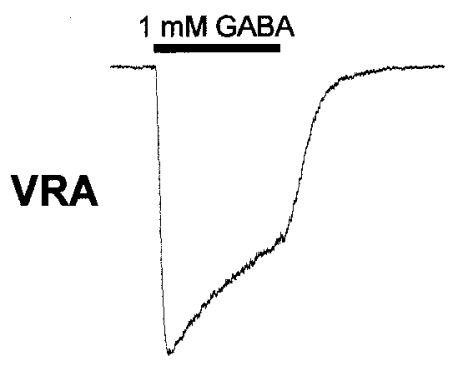

B2

1 mM GABA $10 \mu \mathrm{M}$ Bicuculline

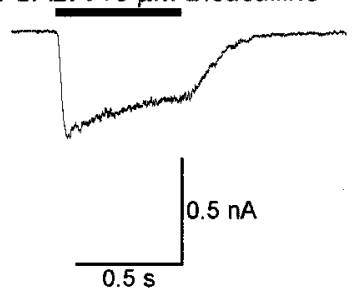

A3

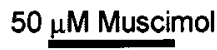

$50 \mu \mathrm{M}$ Muscimol

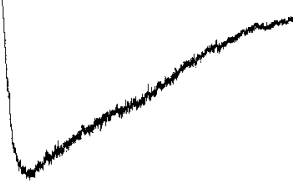

B3

$50 \mu \mathrm{M}$ Muscimol

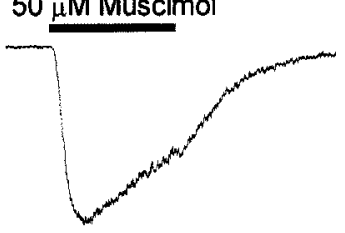

Table 2. $\mathrm{GABA}_{\mathrm{A}}$ currents are comparable in ORAs and VRAs

\begin{tabular}{|c|c|c|c|}
\hline & ORA & VRA & ORA/VRA \\
\hline \multicolumn{4}{|l|}{ GABA (1 mM) } \\
\hline $\mathrm{A}_{\mathrm{P}}(\mathrm{pA})$ & $-829 \pm 259(n=6)$ & $-1092 \pm 359(n=5)$ & 0.76 \\
\hline $\mathrm{CD}(\mathrm{pA} / \mathrm{pF})$ & $107.8 \pm 19.7(n=6)$ & $32.4 \pm 2.2(n=5)$ & 3.3 \\
\hline $\mathrm{A}_{\mathrm{d}} / \mathrm{A}_{\mathrm{P}}(\%)$ & $56.5 \pm 4.8$ & $69.3 \pm 10$ & \\
\hline \multicolumn{4}{|l|}{ Muscimol $(50 \mu \mathrm{M})$} \\
\hline $\mathrm{A}_{\mathrm{P}}(\mathrm{pA})$ & $-719 \pm 222(n=6)$ & $-840 \pm 442(n=5)$ & 0.86 \\
\hline $\mathrm{CD}(\mathrm{pA} / \mathrm{pF})$ & $98.0 \pm 33.4(n=6)$ & $21.6 \pm 7.0(n=5)$ & 4.5 \\
\hline \multicolumn{4}{|l|}{ Bicuculline $(10 \mu \mathrm{M})$} \\
\hline $\begin{array}{l}\% \text { of inhibition of GABA } \\
(1 \mathrm{~mm}) \text {-induced current }\end{array}$ & $58 \pm 10(n=6)$ & $69 \pm 8(n=5)$ & \\
\hline
\end{tabular}

Values are in mean \pm SEM with cell numbers in parentheses. $A_{P}$ and $A_{d}$ are peak and current amplitudes at the end of GABA pulses, respectively. CD, Current density calculated for capacitance differences. None of the apparent differences between ORAs and VRAs were significant by Student's $t$ test.

\section{DISCUSSION}

\section{FIAs show heterogeneity in functional glutamate transporter expression}

A large body of evidences suggests that the majority of presynaptically released Glu is taken up by astrocytes (Anderson and Swanson, 2000). However, it has not been shown previously that a group of protoplasmic astrocytes within a specific brain region, which are also GFAP immunoreactive, have no functional GTs. Because the GT currents were not detectable in ORAs from older animals, the lack of functional GTs appears not to be developmentally restricted but represents a characteristic feature of ORAs. This heterogeneity requires a reconsideration of the diversity of astrocytes in terms of their function in glutamate homeostasis.

We select cells in our preparation based on a bushy, processbearing morphology, and these cells are always GFAP + immunocytochemically (Zhou and Kimelberg, 2000; Zhou et al., 2000). Heterogeneity for GT current expression has not been reported 
from comparable studies on hippocampal astrocytes in situ (Bergles and Jahr, 1997, 1998; Lüscher et al., 1998; Diamond and Jahr, 2000). Possible reasons might be that these investigators identified astrocytes based on the criteria of the cell showing a low input resistance, very negative membrane potential, and dominant $\mathrm{K}_{\mathrm{OHM}}$. VRAs from FIAs show all of these properties (Zhou and Kimelberg, 2000). Therefore, VRAs may well represent the astrocytes selected in the in situ studies just mentioned. However, bushy, process-bearing protoplasmic astrocytes in slices exhibiting similar properties to our ORAs, i.e., dominant voltagegated $\mathrm{K}^{+}$and $\mathrm{Na}^{+}$conductances, and relatively low resting membrane potentials have also been described (Bordey and Sontheimer, 1997; McKhann et al., 1997; D'Ambrosio et al., 1998). Thus, there are no reasons to doubt their existence in situ.

The ion current profiles and high AMPA-R current densities of ORAs are similar to cells in vivo that are positive for the chondroitin sulfate proteoglycan NG2 (Bergles et al., 2000) and are usually referred to as oligodendrocyte precursor cells (Ong and Levine, 1999). We therefore double stained our preparation for both NG2 and GFAP and found that the ORAs and VRAs selected on the basis of their morphology as bushy astrocytes all stained for GFAP but never for NG2. This was found in three preparations from P8-P24 animals (G. P. Schools, M. Zhou, and H. K. Kimelberg, unpublished observations). A large number of cells in the preparation did stain for NG2, but their morphology was quite different and resembled the population of GFAP"complex" cells described previously in a publication from our laboratory that also had current profiles resembling those of ORAs (Zhou et al., 2000). These cells in our preparation have a small round soma and short fine processes that were not as extensive as those reported for NG2+ cells in slices (Bergles et al., 2000). In our current preparations, some of these NG2positive cells often had long fine processes. It appears that considerable lengths of these fine processes may be removed during isolation and/or staining, perhaps because they are more delicate than the thicker processes present on the GFAP + astrocytes.

An immunocytochemical study at the electron microscopic (EM) level reported that GTs varied in their density within and between astrocytes but that no astrocytes were unlabeled (Chaudhry et al., 1995). The absence of functional GT currents in ORAs is inconsistent with this observation. However, in the EM study, the antibody raised against an amino acid fragment of GT clearly cannot make distinctions between functional and nonfunctional proteins.

\section{FIAs are heterogeneous in AMPA-R expression}

Work commencing in 1984 has consistently shown that AMPA-Rs are present in GFAP+ cells in primary culture (Bowman and Kimelberg, 1984; Kettenmann et al., 1984), astrocytes in situ (Steinhäuser et al., 1994), and a population of freshly isolated S100 $\beta+/$ GFAP - astrocytes from hippocampus (Seifert et al., 1997). However, there has not been any study revealing different functional AMPA-R expression within GFAP+ astrocytes. We now show that functional AMPA-R is not a uniform property of GFAP + astrocytes but that morphologically indistinguishable astrocytes have a 40 -fold difference in the surface membrane density of AMPA-R currents. The fact that the AMPA current density of ORA was the same in astrocytes from P25-P30 as in P7-P14 implies that the predominant expression of AMPA-R on ORAs is not developmentally restricted but represents a persistent feature of ORAs in older animals.

\section{AMPA-Rs and glutamate transporter on astrocyte somas and processes}

Bergles and Jahr (1997) showed that glutamate-evoked currents measured from excised patches of hippocampal astrocyte somas were not affected by AMPA antagonists, leading to the conclusion that AMPA-Rs are not present on these soma. Given the likely correspondence of their identified astrocytes with our VRAs, this is, in general, consistent with our finding that VRAs express marginal AMPA-R currents. However, AMPA-R antagonist-sensitive currents always coexisted with GT currents in our study. These differences could be reconciled if the small AMPA-R currents in our whole-cell recording are from astrocytic processes of VRAs, and immunocytochemical studies in situ do show that GTs are differently distributed along the plasma membrane of the same astrocyte (Chaudhry et al., 1995). Second, our whole-cell Glu $\mathrm{EC}_{50}$ for GT currents $(4 \mu \mathrm{M})$ was 3.25-fold lower than the value of $13 \mu \mathrm{M}$ obtained from the somatic patches (Bergles and Jahr, 1997). The fact that GLT-1 coexists with GLAST at younger ages (Furuta et al., 1997; Lehre and Danbolt, $1998)$ and that the Glu affinity of GLT-1 $\left(K_{\mathrm{M}}\right.$ of $\left.2 \mu \mathrm{M}\right)$ (Pines et al., 1992) is 6.5-fold higher than GLAST ( $K_{\mathrm{M}}$ of $13 \mu \mathrm{M}$, Klockner et al., 1994) suggests that the difference in Glu affinities between whole-cell and patches could reflect a nonuniform subcellular distribution of different GT isoforms in astrocytes, such that GLT-1 is dominantly located in processes because our whole-cell $\mathrm{EC}_{50}$ was much closer to the $K_{\mathrm{M}}$ of GLT-1.

\section{Interaction of AMPA-Rs and glutamate transporters}

We found that blockade of AMPA-R activation increased steadystate GT currents by $\sim 40 \%$ in VRAs (Fig. $2 B$ ). Based on the GT-associated anion conductance reflecting the Glu translocation cycle of GTs, this phenomenon suggests a previously unrevealed AMAP-R-mediated inhibition of this process. Judging from the marginal expression of AMPA-Rs by VRAs, this inhibition is unlikely to be caused by a rapid decrease in transmembrane $\mathrm{Na}^{+}$ gradient attributable to AMPA-R activation. Because a saturating Glu concentration (10 $\mathrm{mm})$ was used in the experiments and GT typically shows a much higher Glu affinity than AMPA-R, substrate competition inhibition also seems an unlikely explanation. An additional exploration of the underling mechanism needs additional studies. Interestingly, astrocytic AMPA-R shows a Glu affinity (Steinhäuser and Gallo, 1996) that is at least 10-fold lower than GTs (Palacin et al., 1998). Thus, astrocytic AMPA-R has been suggested to be activated only in response to a large transient Glu rise after marked excitatory synaptic release in situ (Dzubay and Jahr, 1999). In contrast to this, high Glu affinity GTs work at low Glu concentration in clearing the extracellular [Glu] below the level at which neuronal excitotoxicity occurs. If this AMPA-R-mediated inhibition of GT activity exists in vivo, it should only occur in response to repetitively raised Glu transients to ensure activation of astrocytic AMPA-Rs. Therefore, the inhibition would be determined by the intensity of the excitatory synaptic transmission.

\section{Functional and pathological implications}

Physiologically, the hippocampus is highly associated with memory processing, and long-term potentiation (LTP) in the hippocampus is a generally accepted measurable model for memory formation. In the hippocampal CA1 region, it has been shown that postsynaptic activation of the NMDA receptor is necessary for the induction of LTP, and recent evidence has shown that consistent glutamate spillover from neighboring synapses can 
selectively activate NMDA receptor in adjacent synapses (Kullmann and Asztely, 1998). Morphological studies show that $\sim 40 \%$ of hippocampal synapses are not surrounded by astrocytic processes (Ventura and Harris, 1999), a striking difference between this region and the cerebellum in which the dendritic spines of Purkinje cells are completely covered by astroglial sheaths (Spacek, 1985). Also, if some of the $60 \%$ of hippocampal synapses surrounded by astrocytic processes include processes from ORAs, these synapses could maintain a higher local Glu concentration for constant postsynaptic NMDA activation.

The fact that numerous synapses are not invested by astrocytic processes (Ventura and Harris, 1999) and that $~ 50 \%$ of GFAP+ astrocytes in CA1, in P7-P35 animals, consist of ORAs (Zhou and Kimelberg, 2000), may also explain why the hippocampus is one of the brain regions highly vulnerable to glutamate release under pathological conditions (Stoltenburg-Didinger, 1994).

In conclusion, we have shown that freshly isolated GFAP+ astrocytes from the CA1 region of the hippocampus show a remarkable heterogeneity in their expression of functional GT current, which correlates inversely with expression of AMPA-R currents. In contrast, $\mathrm{GABA}_{\mathrm{A}}$ receptor currents are comparable in both types of astrocytes. Together with our previous findings of marked differences in $\mathrm{K}^{+}$and $\mathrm{Na}^{+}$channel expression (Zhou and Kimelberg, 2000), this implies a marked division of labor between morphologically identical astrocytes in these important characteristics. Hypotheses regarding the functional significance of these two types of cells will, at a minimum, require knowledge of how they are arranged relative to other cell types in the CA1 region. These questions need to be resolved by histological techniques using suitable markers for ORAs and VRAs.

\section{REFERENCES}

Anderson CM, Swanson RA (2000) Astrocyte glutamate transport: review of properties, regulation, and physiological functions. Glia $32: 1-14$.

Baranano DE, Ferris CD, Snyder SH (2001) Atypical neural messengers. Trends Neurosci 24:99-106.

Bergles DE, Jahr CE (1997) Synaptic activation of glutamate transporters in hippocampal astrocytes. Neuron 19:1297-1308.

Bergles DE, Jahr CE (1998) Glial contribution to glutamate uptake at Schaffer collateral-commissural synapses in the hippocampus. J Neurosci 18:7709-7716.

Bergles DE, Roberts JD, Somogyi P, Jahr CE (2000) Glutamatergic synapses on oligodendrocyte precursor cells in the hippocampus. Nature 405:187-191.

Bordey A, Sontheimer H (1997) Postnatal development of ionic currents in rat hippocampal astrocytes in situ. J Neurophysiol 78:461-477.

Bowman CL, Kimelberg HK (1984) Excitatory amino acids directly depolarize rat brain astrocytes in primary culture. Nature 311:656-659.

Brockhaus J, Deitmer JW (2000) Developmental downregulation of ATP-sensitive potassium conductance in astrocytes in situ. Glia 32:205-213.

Chaudhry FA, Lehre KP, van Lookeren Campagne M, Ottersen OP, Danbolt NC, Storm-Mathisen J (1995) Glutamate transporters in glial plasma membranes: highly differentiated localizations revealed by quantitative ultrastructural immunocytochemistry. Neuron 15:711-720.

D'Ambrosio R, Wenzel J, Schwartzkroin PA, McK hann II GM, Janigro D (1998) Functional specialization and topographic segregation of hippocampal astrocytes. J Neurosci 18:4425-4438.

Diamond JS, Jahr CE (2000) Synaptically released glutamate does not overwhelm transporters on hippocampal astrocytes during highfrequency stimulation. J Neurophysiol 83:2835-2843.

Dzubay JA, Jahr CE (1999) The concentration of synaptically released glutamate outside of the climbing fiber-Purkinje cell synaptic cleft. J Neurosci 19:5265-5274.

Fairman WA, Vandenberg RJ, Arriza JL, Kavanaugh MP, Amara SG (1995) An excitatory amino-acid transporter with properties of a ligand-gated chloride channel. Nature 375:599-603.

Fraser DD, Duffy S, Angelides KJ, Perez-Velazquez JL, Kettenmann H, MacVicar BA (1995) $\mathrm{GABA}_{\mathrm{A}}$ /benzodiazepine receptors in acutely isolated hippocampal astrocytes. J Neurosci 15:2720-2732.

Furuta A, Rothstein JD, Martin LJ (1997) Glutamate transporter pro- tein subtypes are expressed differentially during rat CNS development. J Neurosci 17:8363-8375.

Kettenmann H, Backus KH, Schachner M (1984) Aspartate, glutamate and gamma-aminobutyric acid depolarize cultured astrocytes. Neurosci Lett 52:25-29.

Klockner U, Storck T, Conradt M, Stoffel W (1994) Functional properties and substrate specificity of the cloned L-glutamate/L-aspartate transporter GLAST-1 from rat brain expressed in Xenopus oocytes. J Neurosci 14:5759-5765.

Kullmann DM, Asztely F (1998) Extrasynaptic glutamate spillover in the hippocampus: evidence and implications. Trends Neurosci 21:8-14.

Lehre KP, Danbolt NC (1998) The number of glutamate transporter subtype molecules at glutamatergic synapses: chemical and stereological quantification in young adult rat brain. J Neurosci 18:8751-8757.

Levy LM, Warr O, Attwell D (1998) Stoichiometry of the glial glutamate transporter GLT-1 expressed inducibly in a Chinese hamster ovary cell line selected for low endogenous $\mathrm{Na}^{+}$-dependent glutamate uptake. J Neurosci 18:9620-9628.

Liu J, Bernabeu R, Lu A, Sharp FR (2000) Neurogenesis and gliaogenesis in the postischemic brain. The Neuroscientist 6:362-370.

Lüscher C, Malenka RC, Nicoll RA (1998) Monitoring glutamate release during LTP with glial transporter currents. Neuron 21:435-441.

McCarren M, Alger BE (1987) Papain effects on rat hippocampal neurons in the slice preparation. Neurosci Lett 78:307-310.

McKhann GM, D'Ambrosio R, Janigro D (1997) Heterogeneity of astrocyte resting membrane potentials and intercellular coupling revealed by whole-cell and gramicidin-perforated patch recordings from cultured neocortical and hippocampal slice astrocytes. J Neurosci 17:6850-6863.

Ong WY, Levine JM (1999) A light and electron microscopic study of NG2 chondroitin sulfate proteoglycan-positive oligodendrocyte precursor cells in the normal and kainate-lesioned rat hippocampus. Neuroscience 92:83-95.

Otis TS, Jahr CE (1998) Anion currents and predicted glutamate flux through a neuronal glutamate transporter. J Neurosci 18:7099-7110.

Otis TS, Kavanaugh MP (2000) Isolation of current components and partial reaction cycles in the glial glutamate transporter EAAT2. J Neurosci 20:2749-2757.

Palacin M, Estevez R, Bertran J, Zorzano A (1998) Molecular biology of mammalian plasma membrane amino acid transporters. Physiol Rev 4:969-1054.

Pines G, Danbolt NC, Bjoras M, Zhang Y, Bendahan A, Eide L, Koepsell H, Storm-Mathisen J, Seeberg E, Kanner BI (1992) Cloning and expression of a rat brain L-glutamate transporter. Nature 360:464-467.

Porter JT, McCarthy KD (1996) Hippocampal astrocytes in situ respond to glutamate released from synaptic terminals. $J$ Neurosci 16:5073-5081.

Privat A, Rataboul P (1986) Fibrous and protoplasmic astrocytes. In: Astrocytes: development, morphology, and regional specialization of astrocytes, Vol 1 (Fedoroff S, Vernadakis A, eds), pp 105-129. Orlando: Academic.

Rothstein JD, Dykes-Hoberg M, Pardo CA, Bristol LA, Jin L, Kuncl RW, Kanai Y, Hediger MA, Wang YF, Schielke JP, Welty DF (1996) Knockout of glutamate transporters reveals a major role for astroglial transport in excitotoxicity and clearance of glutamate. Neuron 16:675-686.

Schools GP, Kimelberg HK (2001) Metabotropic glutamate receptors in freshly isolated astrocytes from rat hippocampus. Prog Brain Res 132:311-321.

Seifert G, Zhou M, Steinhäuser C (1997) Analysis of AMPA-R properties during postnatal development of mouse hippocampal astrocytes. J Neurophysiol 78:2916-2923.

Spacek J (1985) Three-dimensional analysis of dendritic spines. III. Glial sheath. Anat Embryol (Berl) 171:245-252.

Steinhäuser C, Gallo V (1996) News on glutamate receptors in glial cells. Trends Neurosci 19:339-345.

Steinhäuser C, Jabs R, Kettenmann H (1994) Properties of GABA and glutamate responses in identified glial cells of the mouse hippocampal slice. Hippocampus 4:19-35.

Stoltenburg-Didinger G (1994) Neuropathology of the hippocampus and its susceptibility to neurotoxic insult. Neurotoxicology 15:445-450.

Ventura R, Harris KM (1999) Three-dimensional relationships between hippocampal synapses and astrocytes. J Neurosci 19:6897-6906.

Wadiche JI, Kavanaugh MP (1998) Macroscopic and microscopic properties of a cloned glutamate transporter/chloride channel. J Neurosci 18:7650-7661.

Wadiche JI, Amara SG, Kavanaugh MP (1995) Ion fluxes associated with excitatory amino acid transport. Neuron 15:721-728.

Zhou M, Kimelberg HK (2000) Freshly isolated astrocytes show two distinct current patterns and different $\left[\mathrm{K}^{+}\right]_{\mathrm{o}}$ uptake capabilities. J Neurophysiol 84:2746-2757.

Zhou M, Schools GP, Kimelberg HK (2000) GFAP mRNA positive glia acutely isolated from rat hippocampus predominantly show complex current patterns. Brain Res Mol Brain Res 76:121-131. 